\title{
KEBERLANJUTAN USAHA TANI MINA PADI DI KALURAHAN SUMBERAGUNG KAPANEWON MOYUDAN DAERAH ISTIMEWA YOGYAKARTA
}

\author{
Mesalia Kriska*, Harsoyo, Rezki Putri Sulami, Novam Tri Wikarno Putra, Yenni Kusuma \\ Departemen Sosial Ekonomi Pertanian, Fakultas Pertanian, Universitas Gadjah Mada \\ Jl. Flora, Bulaksumur, Karang Malang, Caturtunggal, Depok, Sleman, Yogyakarta 55281 \\ *Corresponding author: mesalia.kriska@mail.ugm.ac.id
}

\begin{abstract}
Mina padi is a rice-fish integrated farming system that could increase agricultural field productivity. By implementing this innovation, agricultural land production could increase, and farmers will benefit from two different commodities, namely rice and fish. The involvement of mina padi farmer groups and support from the agricultural extension officer is needed to achieve maximum results in implementing of Mina padi cultivation. One of many areas that have already been implementing a mina padi farming system in the Special Region of Yogyakarta is Sumberagung Village, Moyudan District. In Sumberagung Village, there are 5 mina padi groups with a total of around 64 members that are still actively running mina padi business. The main aim of this study is to determine the sustainability of mina padi farming in Sumberagung Village, Moyudan District, Sleman Regency. The analytical framework used in this study is the Threats, Weakness, Opportunity, and Strength framework by analyzing the threats, weaknesses, opportunities, and strengths of the Mina padi group business activities. This analysis will provide a sustainable development strategy for the mina padi farming system in Sumberagung Village, Moyudan District. The strategies that would sustain mina padi farming business sustainability are intensifying the mina padi farming field, using the tanam jajar legowo (tajarwo) farming system, and reducing pesticide usage, developing mina padi agritourism, and organizing training for mina padi to the younger generation.
\end{abstract}

Keywords: mina padi, strategy, sustainability of agriculture

\begin{abstract}
Abstrak: Budidaya mina padi adalah budidaya terpadu ikan dan padi dalam satu hamparan sawah yang dapat meningkatkan produktivitas lahan sawah. Penerapan inovasi tersebut akan meningkatkan produktivitas lahan pertanian dan petani akan memiliki hasil panen dari dua komoditas yang berbeda yaitu padi dan ikan. Untuk mencapai hasil yang maksimal dalam pelaksanaan budidaya mina padi dilakukan dengan melibatkan kelompok tani mina padi dan dibantu oleh penyuluh lapangan yang bertugas. Salah satu daerah di Daerah Istimewa Yogyakarta yang melakukan kegiatan budidaya mina padi adalah Kalurahan Sumberagung Kapanewon Moyudan. Di desa tersebut terdapat 5 kelompok tani mina padi yang masih aktif hingga saat ini dengan total jumlah anggota sebanyak 64 orang. Tujuan penelitian ini adalah untuk mengetahui keberlanjutan usaha tani mina padi di Kalurahan Sumberagung Kapanewon Moyudan Kabupaten Sleman. Kerangka analisis yang digunakan pada penelitian ini yaitu kerangka Threats, Weakness, Opportunity, dan Strength dengan melakukan analisis terhadap ancaman, kelemahan, peluang, dan kekuatan kelompok mina padi dalam menjalankan usahanya. Setelah dilakukan analisis tersebut, maka akan disusun strategi pengembangan budidaya mina padi di Kalurahan Sumberagung Kapanewon Moyudan. Strategi yang dapat dilakukan untuk dapat menjalankan keberlanjutan usaha mina padi yaitu intensifikasi lahan mina padi, penggunaan sistem tajarwo dan pengurangan penggunaan bahan kimia dalam menangani OPT,
\end{abstract}


pengembangan lahan mina padi menjadi tujuan wisata, serta menyelenggarakan pelatihan mina padi kepada generasi muda.

Kata kunci: mina padi, strategi, keberlanjutan pertanian

\section{PENDAHULUAN}

Produktivitas lahan pertanian kini mulai dilihat tidak hanya dari hasil per lahannya saja, namun juga dilihat dari keberagaman produk yang dapat dihasilkan dalam sebuah lahan. Intesifikasi lahan yang dilakukan oleh pemerintah saat ini tidak hanya difokuskan untuk bisa menghasilkan produk pokok saja, namun juga diharapkan mampu memberikan pendapatan lain dari produk yang lain. Salah satu upaya yang dilakukan pemerintah yaitu mengenalkan inovasi budidaya mina padi kepada petani yang memiliki lahan dengan ketersediaan air yang cukup. Peraturan Pemerintah dalam Juknis Pelaksanaan Budidaya Mina Padi 2018 mensyaratkan lahan yang digunakan budidaya mina padi adalah 1) daerah irigasi teknis yang bisa diatur pengairannya dan menyediakan air kapan saja, 2) lahan mina padi memiliki kualitas air yang baik untuk pemeliharaan ikan, dan 3) lahan menggunakan varietas unggul yang tahan genangan dan mengguanakan bibit ikan yang sehat.

Budidaya mina padi dipilih sebagai alternatif untuk menggantikan budidaya padi secara konvensional atau monokultur. Monokultur padi tidak dapat menyediakan pasokan pangan yang berkelanjutan serta dapat mengancam kelestarian lingkungan jangka panjang (Ahmed dan Garnett, 2011). Budidaya mina padi adalah budidaya terpadu ikan dan padi dalam satu area sawah yang sama, yang dapat meningkatkan produktivitas lahan. Penerapan inovasi tersebut, akan meningkatkan produktivitas lahan pertanian dan petani akan memiliki hasil panen dari dua komoditas yang berbeda yaitu padi dan ikan. Selain itu, mina padi ikut mendukung gerakan pertanian organik yang menawarkan produk pangan yang sehat dan menjaga lingkungan dari bahan-bahan kimia yang berlebih (Hazra et al., 2016).

Kesuksesan penerapan budidaya mina padi agar bisa mencapai hasil yang maksimal tidak hanya dilakukan oleh perseorangan secara mandiri, namun melibatkan kelompok tani mina padi dan dibantu oleh penyuluh lapangan yang bertugas. Salah satu daerah di Daerah Istimewa Yogyakarta yang melakukan kegiatan budidaya mina padi adalah Kalurahan Sumberagung Kapanewon Moyudan. Di desa tersebut terdapat 5 kelompok tani mina padi yang masih aktif hingga saat ini dengan total jumlah anggota sekitar 64 orang. Ketersediaan air yang dapat dipenuhi sepanjang tahun membuat pemerintah memilih daerah tersebut untuk penerapan inovasi mina padi.

$$
\text { Penerapan inovasi mina padi }
$$
memberikan produktivitas tambahan bagi anggotanya. Keuntungan lain yang bisa didapat dari mina padi ini adalah mengurangi penggunaan pestisida kimia sehingga hasil panen lebih organik, mengurangi biaya produksi, serta mengurangi dampak lingkungan (Dey et al., 2018). Hasil wawancara menunjukkan bahwa petani mina padi di Moyudan pada tahun pertama berhasil menerapkan metode ini dan dapat memanen tidak hanya padi, namun juga ikan sebagai sumber pendapatan, sehingga petani mau melanjutkan budidaya dengan bantuan pasokan pupuk, benih padi dan benih ikan dari dinas pertanian. Peran penyuluh yang mendampingi dalam kegiatan pra budidaya hingga pasca panen membuat pengetahuan petani lebih meningkat sehingga hasil yang diperoleh sesuai dengan harapan.

Pendampingan yang dilakukan oleh penyuluh tidak selalu menjamin keberhasilan penerapan budidaya mina padi, sehingga terdapat faktor yang dapat mendorong faktor yang dapat menghambat berkembangnya usaha. Faktor-faktor tersebut dapat diketahui dengan analisis SWOT. Analisis SWOT merupakan salah satu alat bantu yang dapat digunakan untuk menganalisis faktor internal dan faktor eksternal untuk membantu memahami secara sistematis suatu rencana strategis yang dapat dilakukan oleh suatu individu atau kelompok untuk menghadapi suatu masalah tertentu (Patnaik dan Poyyamoli, 2015). SWOT sendiri merupakan akronim dari Strengths (Kekuatan), Weaknesses (Kelemahan), Opportunities (Peluang), dan Threats (Ancaman). Analisis SWOT sering digunakan dalam penilaian 
rencana strategis suatu organisasi, laporan hasil studi tentang suatu organisasi, untuk membandingkan dua organisasi, hingga membandingkan beberapa organisasi (Helms dan Nixon, 2010).

Analisis SWOT mengidentifikasi berbagai kelebihan, kekurangan, ancaman, dan peluang yang ada dalam budidaya mina padi ini kemudian dapat dilihat apakah budidaya yang dilakukan dapat menunjukkan adanya keberlanjutan yang dapat memberi keuntungan bagi petani sebagai pelaku utama atau tidak. Analisis dilakukan dengan membuat matriks SWOT. Matriks SWOT merupakan alat penting dalam penting dalam pengembangan strategi yang didasari dari relasi antara Strengths (Kekuatan), Weaknesses (Kelemahan), Opportunities (Peluang), dan Threats (Ancaman) yang telah teridentifikasi dari SWOT (Aslan et al., 2012).

Berdasarkan penelitian yang dilakukan oleh Muhammad (2018) identifikasi faktor internal dan eksternal dapat bermanfaat untuk mengetahui titik yang menjadi kekuatan dan kelemahan serta mengidentifikasi peluang dan ancaman dalam pengembangan usahatani. Dengan menggunakan analisis matriks SWOT diperoleh beberapa alternatif strategi yang nantinya dapat digunakan supaya usaha dapat berjalan secara berkelanjutan. Dari adanya hal tersebut maka didapat tujuan penelitian. Tujuan dari penelitian ini adalah untuk mengetahui keberlanjutan usaha tani mina padi di Kalurahan Sumberagung Kapanewon Moyudan Kabupaten Sleman.

\section{METODE PENELITIAN}

Penelitian menggunakan metode kualitatif untuk menentukan cara mencari, mengumpulkan, mengolah dan menganalisis data hasil penelitian dengan pertimbangan masalah yang diangkat bersifat sosial dan dinamis. Format desain penelitian kualitatif terdiri dari tiga model, yaitu format deskriptif, format verifikasi, dan format grounded research. Penelitian ini menggunakan metode kualitatif dengan desain deskriptif, yaitu penelitian yang dengan menarik permasalahan yang ada di masyarakat untuk kemudian disimpulkan menjadi sebuah ciri atau gambaran tentang kondisi, kemudian menarik kesimpulan (Bungin, 2008). Kerangka analisis yang digunakan pada penelitian ini yaitu kerangka SWOT dengan melakukan analisis terhadap ancaman, kelemahan, peluang, dan kekuatan kelompok mina padi dalam menjalankan usahanya. Setelah dilakukan analisis tersebut, kemudian disusun strategi pengembangan budidaya mina padi di Kalurahan Sumberagung Kapanewon Moyudan.

Subjek penelitian adalah petani yang tergabung dalam kelompok mina padi dan objek penelitian adalah mengenai analisis kekuatan, kelemahan, hambatan, dan tantangan dalam melaksanakan usaha tani mina padi di Kalurahan Sumberagung Kapanewon Moyudan Kabupaten Sleman.

\section{HASIL DAN PEMBAHASAN}

Inovasi mina padi merupakan inovasi yang megintegrasikan antara hasil pertanian dengan perikanan yang didiseminasikan oleh Dinas Pertanian, Pangan, dan Perikanan Kabupaten Sleman pertama kali di Kapanewon Moyudan pada awal tahun 2014. Bagian yang bertanggung jawab pada penyebarluasan inovasi mina padi ini adalah Bidang Perikanan dengan sasaran utama pada kelompok pembudidaya ikan. Mina padi merupakan salah satu budidaya pertanian yang menggabungkan penanaman padi dengan budidaya ikan air tawar. Budidaya mina padi merupakan salah satu inovasi yang dikembangkan dengan tujuan untuk diversifikasi usaha tani sehingga tidak hanya melakukan usaha tani padi konvensial saja. Mina padi juga merupakan usaha intensifikasi pertanian yang efektif, menggabungkan dan memberi kontribusi jasa ekosistem dalam produksi pertanian dan meningkatkan keberlanjutan (Bai et al., 2019).

Penyebarluasan inovasi mina padi ini dilakukan dengan mengundang ketua kelompok pembudidaya ikan untuk mengikuti pelatihan budidaya mina padi di Dinas Pertanian, Pangan, dan Perikanan di Kabupaten Sleman. Ketua kelompok pembudidaya ikan kemudian diberikan kesempatan untuk mendiskusikan bersama dengan anggota kelompok lainnya untuk memutuskan untuk menerima inovasi mina padi ini atau tidak. Setelah menemui kesepakatan kelompok untuk menerapkan inovasi mina padi ini, kemudian diberikan pendampingan serta bantuan dalam bentuk benih ikan, pakan, mulsa, jaring dan lain 
sebagainya. Pendampingan dilakukan oleh Penyuluh Pertanian Lapangan (PPL). Penerapan awal inovasi mina padi ini dilakukan dengan demonstrasi plot yang dilaksanakan di lahan sawah masing-masing kelompok.

Pengembangan usaha Mina Padi di Kalurahan Sumberagung telah berjalan selama kurang lebih enam tahun. Pada awalnya hanya terdapat dua kelompok yang mengembangkan budidaya mina padi ini kemudian seiring berjalannya waktu berkembang menjadi lima kelompok.

Perkembangan tersebut didukung dengan adanya lahan sawah, sumber air yang memadai, serta dukungan dari penyuluh lapangan di Kalurahan Sumberagung. Dengan adanya

Tabel 1. Matriks SWOT budidaya mina padi Kalurahan Sumberagung

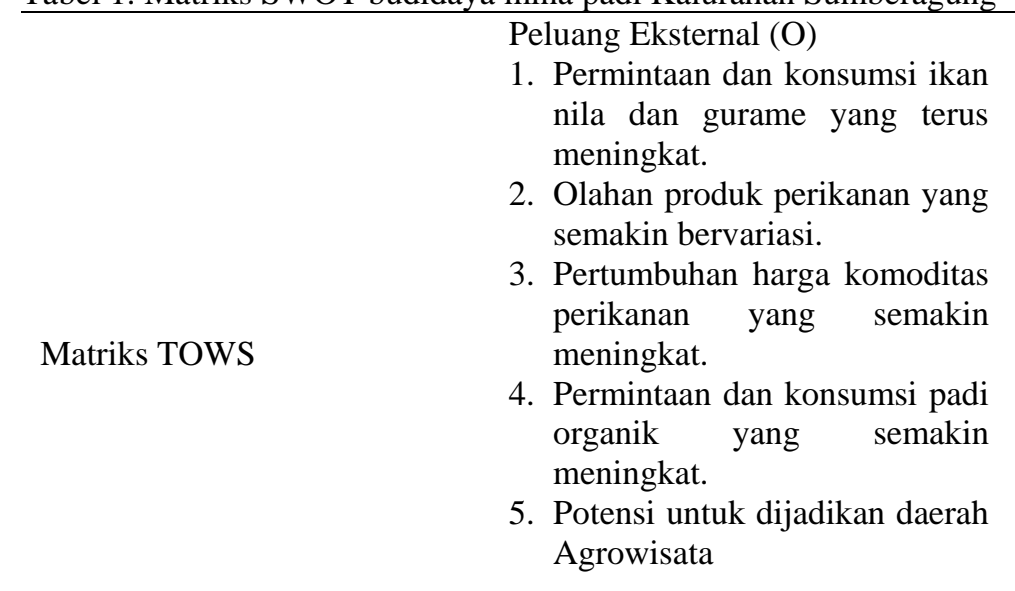

Tantangan Eksternal (T)

1. Banyaknya hama berang-berang yang mengancam budidaya mina padi.

2. Semakin banyaknya kompetitor yang masuk dalam usaha tani padi organik dan usaha perikanan air tawar.

3. Biaya benih dan pakan yang semakin meningkat.

4. Kurangnya komunikasi dengan Penyuluh Pertanian Lapangan (PPL) karena pandemi COVID19 dan adanya pergantian PPL.

5. Regenerasi pertanian yang lamban karena minat pemuda terhadap pertanian menurun

Kekuatan Internal (S)

1. Adanya modal baik dari pribadi dan bantuan dinas terkait

2. Sarana dan Prasarana produksi yang memadai

3. Petani mampu membibitkan benih sendiri (benih padi maupun ikan)

4. Kemampuan petani dalam budidaya minapadi baik

5. Biaya pengendalian Organisme Pengganggu Tanaman (OPT) yang rendah

Kelemahan Internal (W)

1. Mayoritas lahan bukan milik pribadi (sewa).

2. Belum maksimalnya pemanfaatan teknologi informasi.

3. Rata-rata usia petani dan PPL tua.

4. Masih adanya kelompok tani yang tidak memiliki rumah produksi.

5. Debit air yang tidak memadai pada musim tanam kemarau
SO-Strategies

1. Intensifikasi lahan mina padi dengan modal dari dinas terkait, yang didukung dengan sarana dan prasarana yang tersedia (S1-5 dan O1-4)

2. Pengembangan lahan mina padi menjadi tujuan wisata (S1 dan O5)

WO- Strategies

1. Intensifikasi lahan mina padi dengan lahan yang ada, dengan memanfaatkan teknologi informasi yang ada (W1-5 dan O1-4)

\section{ST- Strategies}

1. Penggunaan sistem tajarwo pada penanaman padi dan mengurangi penggunaan bahan kimia agar OPT yang ada bisa menjadi tambahan pakan bagi ikan (S1-5 dan T1-3)

2. Menyelenggarakan pelatihan untuk generasi muda dengan pendampingan petani yang sudah mahir menjalankan budidaya mina padi (S1,2,4 dan T5)

1. Menyelenggarakan pelatihan untuk generasi muda dengan pendampingan petani yang sudah mahir menjalankan budidaya mina padi (W3-5 dan T1-3) 
kelebihan tersebut maka usaha mina padi di Kalurahan Sumberagung ini dapat dipertahankan dan dikembangkan lebih jauh lagi sehingga nantinya dapat berkembang, tidak hanya terbatas pada lima kelompok saja yang mengembangkan usaha mina padi ini. Akan tetapi untuk mempertahankan serta mengembangkan usaha mina padi ini diperlukan suatu strategi. Strategi adalah sejumlah keputusan dan aksi yang ditujukan untuk mencapai tujuan dengan memanfaatkan peluang dan tantangan yang dihadapi dalam lingkungannya (Kuncoro, 2006). Strategi pengembangan usaha mina padi ini dapat disusun dengan melihat pada analisis SWOT yang menganalisis mengenai kelebihan, kekurangan, hambatan dan tantangan. Analisis strategi SWOT dibagi menjadi empat macam diantaranya 1) Strategi WT (Weakness-Treath) menerapkan prinsip meminimalkan baik ancaman maupun kelemahan (minimalminimal), mengurangi ancaman dan mengatasi kekurangan, 2) Strategi WO (WeaknessOpportunity), menggunakan prinsip meminimalkan kelemahan dan memaksimalkan peluang (minimal-maksimal), mengurangi kelemahan, dan menggunakan peluang, 3) Strategi ST (Strength-Treath) menggunakan prinsip memaksimalkan kekuatan dan meminimalkan ancaman (maksimal-minimal), memperkuat keuntungan, dan menghindari resiko, dan 4) Strategi SO (StrengthOpportunity) memaksimalkan kekuatan dan peluang (maksimal-maksimal), meningkatkan manfaat, dan memanfaatkan peluang (Baudino et al., 2017). Berdasarkan hasil penelitian yang dilakukan dengan melakukan pengumpulan data didapati hasil yang disusun dalam matriks SWOT budidaya mina padi Kalurahan Sumberagung yang dapat dilihat pada Tabel 1 .

Hasil analisis SWOT pada Tabel 1 menunjukkan terdapat 4 strategi yang dirumuskan dari temuan strategi di 4 kuadran. Pertama : intensifikasi lahan mina padi yang merupakan temuan di kuadran SO-Strategies dan WO-Strategies. Kedua : penggunaan sistem tajarwo dan pengurangan penggunaan bahan kimia dalam menangani OPT yang merupakan temuan di kuadran ST-Strategies. Ketiga: pengembangan mina padi menjadi tujuan wisata sebagai temuan di kuadran SOStrategies, dan yang terakhir yaitu menyelenggarakan pelatihan mina padi sebagai hasil dari kuadran ST-strategies dan WTStrategies. Berikut adalah rincian strategi yang dapat dilakukan untuk dapat menjalankan keberlanjutan usaha tani mina padi.

\section{Intensifikasi lahan mina padi}

Strategi yang dapat dilakukan untuk mengembangkan mina padi adalah dengan intensifikasi lahan pertanian. Walaupun sudah tersedia lahan, akan tetapi perlu adanya usaha intensifikasi lahan mina padi sehingga pemanfaatan lahan tersebut lebih maksimal. Intensifikasi dilakukan dengan melakukan pengolahan lahan pertanian yang ada dengan sebaik-baiknya untuk meningkatkan hasil pertanian dengan menggunakan berbagai sarana dan prasarana. Intensifikasi lahan ini bertujuan untuk meningkatkan efisiensi penggunaan lahan, khususnya menjaga kesuburan lahan (Hidayati et al., 2019). Intensifikasi lahan dapat dilakukan dengan pengaplikasian pupuk organik, pemberian pakan alami kepada ikan sehingga pakan tersebut apabila tidak termakan dapat terurai dan menjadi pupuk alami, penggunaan bibit padi unggul, pengaturan air irigasi yang baik, pengolahan lahan yang sesuai, dan penanganan budidaya hingga panen yang baik.

\section{Penggunaan sistem tajarwo dan pengurangan penggunaan bahan kimia dalam menangani OPT}

Salah satu masalah dalam budidaya padi adalah adanya Organisme Pengganggu Tanaman (OPT) yang menyerang sehingga dapat menyebabkan penurunan jumlah produksi padi. Mina padi dapat dipilih sebagai solusi untuk mengatasi permasalahan OPT pada padi karena OPT yang menyerang dapat dimangsa oleh ikan yang dibudidayakan bersamaan dengan padi. Dengan adanya hal tersebut tentunya dapat mengurangi bahkan meniadakan penggunaan pestisida kimia atau bahan kimia dalam menangani OPT sehingga hasil panen dari mina padi ini lebih organik. Supaya pengendalian OPT ini dapat berjalan lebih maksimal serta mencegah munculnya penyakit yang disebabkan karena pertumbuhan jamur atau bakteri pada tanaman padi maka dapat dilakukan sistem tanam jajar legowo (tajarwo). Tajarwo merupakan suatu pola tanam dengan mengatur jarak tanam padi bertujuan untuk memberi ruang padi memiliki anakan serta 
jangkauan sinar matahari sehingga dapat meningkatkan produksi padi. Pola tanam ini berselang seling antara dua atau lebih baris tanaman padi dan satu baris kosong. Tajarwo ini merupakan pengembangan dari sistem tegel, dapat diamati baham tanaman yang tumbuh pada baris paling luar menghasilkan hasil yang lebih tinggi.

Usahatani dengan jajar legowo dapat menghasilkan produksi beras sebanyak 3.779,35 kg per musim tanam per hektar, sedangkan produksi beras yang dihasilkan petani padi sawah konvensional sebanyak $3.233,45 \mathrm{~kg}$ per musim tanam per hektar sehingga biaya produksi per unit $(\mathrm{kg})$ beras yang dihasilkan petani padi sawah jajar legowo lebih rendah dibandingkan petani padi sawah konvensional (Purbata et al., 2020). Tanam jajar legowo ini juga sangat cocok diaplikasikan di lahan mina padi, selain memberi banyak keuntungan untuk perkembangan padi, adanya ruang dari jajar legowo ini dapat memperluas area pergerakan ikan ke tengah-tengah area sawah sehingga ikan juga dapat memangsa OPT yang ada di bagian tengah lahan sawah.

\section{Pengembangan lahan mina padi menjadi tujuan wisata}

Berdasarkan temuan pada peluang analisis SWOT, pengembangan usaha mina padi ini tidak hanya terbatas sebagai wahana untuk memproduksi ikan dan padi saja, akan tetapi apabila dikelola dan dikembangkan lebih jauh maka mina padi ini berpotensi sebagai tempat wisata. Usaha mina padi berpotensi untuk dapat dijadikan sebagai tempat wisata karena perpaduan antara kolam ikan ditambah dengan hamparan padi menawarkan pemandangan yang indah dan asri. Selain itu, mina padi ini juga dapat dijadikan sebagai wisata pemancingan atau penangkapan ikan secara langsung dengan jaring kemudian dapat diolah menjadi masakan sehingga juga menawarkan paket wisata kuliner,

Selain itu mina padi ini juga dapat dijadikan sebagai wahana wisata edukasi yang didalamnya mengajarkan bagaimana cara melakukan budidaya mina padi dari pembibitan hingga pemanenan, seperti yang disajikan pada Kampung Mina Padi Samberembe, Kalurahan Candrabirangun, Kapanewon Pakem, Kabupaten Sleman. Dari adanya pengelolaan lahan mina padi menjadi wahana wisata dapat memberikan tambahan pemasukan bagi petani dan desa sehingga pendapatan tidak hanya didapat dari hasil produksi akan tetapi dari tempat wisata tersebut. Tempat budidaya mina padi di Kalurahan Sumberagung ini sendiri sangat berpotensi sebagai tempat wisata karena juga didukung adanya pohon kelapa di sepanjang tepi jalan. Berdasarkan hasil observasi, banyak orang-orang yang sengaja untuk mengunjungi area persawahan di Kalurahan Sumberagung untuk mengambil foto. Strategi yang dapat dilakukan untuk menjadikan lahan mina padi sebagai tempat wisata adalah dengan mengelola dan menata terlebih dahulu tempat yang akan dijadikan sebagai wahana wisata supaya kegiatan wisata tersebut tidak mengganggu dan merusak lahan budidaya. Tempat wisata ini perlu disosialisasikan secara intensif melalui berbagai media baik cetak, elektronik, maupun media sosial sehingga wisata mina padi ini dikenal lebih luas.

\section{Menyelenggarakan pelatihan mina padi kepada generasi muda}

Jumlah dan usia petani masih membuat regenerasi petani yang tidak berjalan baik. Hal tersebut karena kurangnya minat generasi muda untuk melakukan kegiatan pertanian turut mengancam eksistensi budidaya mina padi ini. Apabila tidak ada penerus maka keberadaan budidaya mina padi ini terancam punah sehingga manfaat dari adanya mina padi ini tidak dapat dirasakan oleh generasi selanjutnya. Penelitian yang dilakukan oleh Sularno dan Jauhari (2017) menunjukkan pembinaan tenaga SDM untuk kegiatan mina padi menjadi hal yang sangat penting untuk pengembangan agribisnis mina padi.

Pengembangan SDM pada budidaya mina padi diantisipasi dengan adanya ajakan atau sosialisasi yang dilakukan secara intensif dari berbagai lini, mulai dari stakeholder dari pihak pemerintah maupun swasta, petani yang sudah mahir, serta dukungan dari keluaarga. Generasi muda tertarik dengan adanya usaha yang dapat memberikan penghasilan yang tinggi, maka dari itu perlu adanya penekanan mengenai kelebihan dari mina padi berupa hasil panen berupa beras organik yang memiliki nilai jual yang tinggi, akan tetapi dari hasil panen ikan yang harganya tinggi dipasaran. Pelatihan 
juga perlu diajarkan terus-menerus kepada generasi muda dari penyuluh ataupun petani yang telah mahir dalam melakukan budidaya mina padi sehingga konsep dari budidaya mina padi ini dapat tersampaikan dengan baik tanpa adanya miskonsepsi. Selain itu pelatihan juga perlu menyesuaikan dengan gaya generasi muda sehingga tidak tampak monoton atau terkesan menggurui. Pelatihan dapat dilakukan juga melalui media sosial karena sebagian besar generasi muda suka untuk mengakses sosial media, sehingga pelatihan tersebut dapat dijangkau oleh pemuda dari berbagai wilayah serta mengefisiensikan biaya pelatihan.

Keempat strategi yang diuraikan menjadi strategi utama yang dapat memengaruhi keberlanjutan usaha mina padi di Kapanewon Moyudan yang dianalisis dengan melihat kelebihan, kelemahan, peluang, dan tantangan akan keberadaannya. Dalam menyusun keberlanjutan usaha mina padi di Kapanewon Moyudan, perlu dilakukan koordinasi antar stakeholder untuk bisa melaksanakan strategi yang ada sehingga keberlanjutan mina padi di Kapanewon Moyudan dapat diciptakan dan dipertahankan.

\section{KESIMPULAN}

Berdasarkan analisis kekuatan, kelemahan, peluang, dan tantangan serta melakukan analisis strategi dengan analisis SWOT, strategi yang dapat dilakukan untuk dapat menjalankan keberlanjutan usaha mina padi adalah intensifikasi lahan mina padi, penggunaan sistem tajarwo dan pengurangan penggunaan bahan kimia dalam menangani Organisme Pengganggu Tanaman (OPT), pengembangan lahan mina padi menjadi tujuan wisata, serta menyelenggarakan pelatihan mina padi kepada generasi muda.

Dalam memastikan bahwa keberlanjutan usaha mina padi di Kecamatan Moyudan agar bisa terus berlangung, perlu adanya kerjasama antar kelompok dengan bimbingan dan pendampingan dari stakeholder terkait, seperti Dinas, PPL, Desa, dan pendamping desa untuk bisa mengelola usaha yang ada untuk bisa terus eksis berjalan.

\section{DAFTAR PUSTAKA}

Ahmed, N., \& Garnett, S. T. (2011).
Integratedrice-fish farming in Bangladesh: meeting the challenges of food security. Journal of Food Security, 3(1), 81-92. https://doi.org/10.1007/ s12571-011-0113-8.

Aslan, I., Cinar, O., \& Kumpikaite, V. (2012). Creating strategies from TOWS matrix for strategic sustainable development of Kipas Group. Journal of Business Economics and Management, 13, 96110.

Bai, N., Chen, Y., Zhang, H., Tao, X., \& Zhang, H. (2019). Ecological intensification of rice production through rice-fish co-culture. Journal of Cleaner Production, 234, 1002-1012. https://doi. org/10.1016/j.jclepro.2019.06.238.

Baudino, C., Giuggioli, N. R., Briano, R., Massaglia, S., \& Peano, C. (2017). Integrated methodologies (SWOT, TOWS, LCA ) for improving production chains and environmental sustainability of kiwi fruit and baby kiwi in Italy. Sustainability, 9 (1621), 1-18. https://doi.org/10.3390/su9091621.

Bungin, B. (2008). Analisis Data Penelitian Kualitatif. Jakarta: Raja Grafindo Persada.

Dey, A., Sarma, K., \& Kumar, U. (2018). Prospects of rice-fish farming system for low lying areas in Bihar, India. Organic Agriculture, 9(1), 1-18. https://doi.org/ 10.1007/s13165-017-0204-8.

Hazra, K.K., Swain, D.K., Bohra, A. (2016). Organic rice: Potential production strategies, challenges and prospects. Organic Agriculture, 8, 39-56. https:// doi.org/10.1007/s13165-016-0172-4.

Helms, M. M. \& Nixon, J. (2010). Exploring SWOT analysis-where are we now? A review of academic research from the last decade. Journal of Strategy and Management, 3, 215-251.

Hidayati, F., Yonariza, Y., Nofialdi, N., \& Yuzaria, D. (2019). Intensifikasi lahan 
Kriska, M., Harsoyo, Sulami, R. P., Putra, N. T. W., Kusuma, Y. : Keberlanjutan Usaha Tani..

sistem pertanian terpadu: Sebuah tinjauan. Unri Conference Series: Agriculture and Food Security, 1, 113119. https://doi.org/10.31258/unricsagr. $1 \mathrm{a} 15$.

Kuncoro, M. (2006). Strategi Bagaimana Meraih Keunggulan Kompetitif. Semarang: PT Erlangga.

Muhammad, M. (2018). Analisis SWOT sebagai strategi pengembangan usahatani buah naga merah (Hylocereus costaricensis) Kecamatan Wasile Timur Kabupaten Halmahera Timur. Jurnal Agribisnis Perikanan, 11(1), 28-37. https://doi.org/10.29239/j.agrikan.11.1.2 8-37.
Patnaik, R. \& Poyyamoli, G. (2015). Developingan eco-industrial park in Puducherry Region, India-A SWOT analysis. Journal of Environmental Planning and Management, 58, 976996.

Purbata, A. G., Hadi, S., \& Tarumun, S. (2020). Analisis perbandingan efisiensi produksi padi sawah : antara sistem tanam jajar legowo dan sistem tanam konvensional. Jurnal Ilmiah Pertanian, 16(2), 75-87.

Sularno, S., \& Jauhari, S. (2017). Peluang usaha melalui agribisnis mina padi untuk meningkatkan pendapatan petani. SEPA: Jurnal Sosial Ekonomi Pertanian Dan Agribisnis, 10(2), 268. https://doi.org/ 10.20961/sepa.v10i2.14136. 